CONFERENCIA

\title{
ORIENTACIONES Y DESAFÍOS EN LA TEOLOGÍA BÍBLICA DEL ANTIGUO TESTAMENTO ${ }^{1}$
}

\author{
Georg Fischer, SJ \\ Institut für Bibelwissenschaften und Historische Theologie \\ Universidad de Innsbruck \\ georg.fischer@uibk.ac.at
}

Resumen: Los últimos años han visto un renacimiento de la teología bíblica. Sin embargo, las diferencias entre los diversos libros del Antiguo Testamento y sus características individuales requieren que hablemos de "teologías" en plural. Este artículo reflexiona sobre el papel de la fe y sobre los principales desafíos y problemas con los que se enfrenta hoy el estudio de las teologías bíblicas.

Palabras clave: Teologías. Método. El papel de la fe. Lenguaje teológico. Intepretación cristiana del Antiguo Testamento.

Titel: Orientations and Challenges in the Biblical Theology of the Old Testament

Abstract: Recent years have seen a revival of biblical theology. The differences between the individual books of the OT and their characteristics, however, require us to speak of "theologies" in the plural. This article

1 Este artículo es fruto de una conferencia pronunciada durante la Jornada de “Teología bíblica" organizada por la Pontificia Universidad Gregoriana, Roma, el 10 de mayo de 2017. Agradezco al Departamento de Teología Bíblica por la invitación, a Uriel Salomón Salas, SJ, quien ha traducido y redactado este artículo y a Jorge Blunda por su interés en la publicación de esta contribución. 
reflects on the role of faith and on the major challenges and problems for research in biblical theologies today.

Keywords: Theologies. Methodology. The role of faith. Challenges. Speaking of God. Christian interpretation of the Old Testament.

En los últimos años han aparecido muchos libros y artículos sobre teología bíblica, una señal de la actualidad del tema. En el presente escrito quiero presentar algunas observaciones y experiencias surgidas durante muchos años de investigación en este campo. En un primer paso (1) intento mostrar la necesidad y la justificación de la teología bíblica. Luego (2) son pertinentes orientaciones sobre esta área. Finalmente (3), es útil reconocer los desafíos de la teología bíblica.

\section{Algunas preguntas}

\subsection{En los estudios bíblicos, ¿no es suficiente con la exégesis de cada texto en particular? ¿Por qué es necesaria la teología bíblica?}

Quisiera proponer de entrada dos ejemplos: Ezequiel 9,3-11,23 describe, en tres etapas, cómo Dios deja el templo. Sin embargo, esto no se podría comprender correctamente si no se tiene en cuenta Ez 43,1-5, donde se narra el retorno de Dios al templo. Es decir, se necesita conocer también Ez 43 para poder interpretar Ez 9-112.

Jeremías 12,8 habla del odio divino contra su heredad. Pero si no se tiene en cuenta Jr 31,3, donde se habla de su amor eterno hacia ella, se podría llegar a una comprensión equivocada -y demasiado dura- del Dios bíblico. Ciertamente, Jr 31 "corrige" la imagen de Dios de Jr 12: el odio es limitado; lo que dura por siempre es el amor de Dios, y este como base. El pasaje subsiguiente reacciona al primero y lo sobrepasa ${ }^{3}$.

Como una llamada de atención, estos dos ejemplos demuestran la necesidad de considerar no solamente textos aislados, sino horizontes amplios, desarrollos extensos y libros en su conjunto. Además, la teología,

\footnotetext{
2 Sedlmeier, Das Buch Ezechiel. Kapitel 25-48, 294.

${ }^{3}$ FISCHER, Jeremia 26-52, 182-183.
} 
para ser verdaderamente definida como "bíblica", no se debe limitar a un libro en particular -el de Jueces o Abdías, por ejemplo-, sino que es necesario tener en cuenta varios libros en relación ${ }^{4}$.

\section{2. ¿Es justificado hablar de "teología bíblica” en singular?}

¿Quién podría mezclar una manzana, una ventana y una piedra hablando de ellas como si fueran semejantes y pudieran ser agrupadas bajo un solo concepto? Del mismo modo, sería erróneo hablar de la teología del Antiguo Testamento, insinuando que esta sea "una sola".

De hecho, hay una gran variedad de teologías: el libro de Ester, en hebreo, no contiene mención alguna de Dios. En contraste, Génesis 2-3 habla 20 veces de "Yhwh-Dios", el libro de Isaías llama 26 veces a Dios con el título "el Santo de Israel", mientras que fuera de Isaías solo aparece 6 veces, etc. Estas observaciones señalan que los diversos libros tienen sus características propias, y que inicialmente estas no se deben mezclar de un libro a otro.

Por tanto, la gran variedad de modos en los que la Biblia presenta a Dios exige hablar de teologías bíblicas en plural.

\section{3. ¿Son verdaderamente "teologías" o solamente tienen algunos matices particulares?}

¿Se puede decir que hay un "hablar de Dios" intencional o son los exegetas quienes sistematizan bajo este rótulo algunas de sus observaciones particulares?

Las 20 menciones de la denominación "Yhwh-Dios" en Gn 2-3, sin que esta se encuentre tan siquiera una vez antes o después dentro del Génesis, indican una intervención deliberada del autor. Lo mismo vale para las 26 menciones del título "el Santo de Israel", usado preferentemente en Isaías. El motivo "padres-hijos" aplicado a la relación entre Dios y el pueblo hace las veces de marco en este libro profético (Is 1,2-3 con 66,13) y aparece también en varios puntos intermedios. Dt 32 utiliza 7 veces $\mathbf{x} u r$, "roca", referido a Dios. Así introduce una imagen para comprender la

${ }^{4}$ En este sentido, dada su orientación bíblico-teológica, autores latinoamericanos como José Severino CROATto y Carlos MESTERs han sido ejemplos y puntos de referencia que han enriquecido la interpretación de la Palabra de Dios. 
lealtad, la estabilidad y la seguridad divinas; justamente tres aspectos que representan un punto culminante de la teología del Deuteronomio, la cual más adelante será importante para las teologías de muchos otros libros del AT.

Los grandes libros de la Biblia (como los de la Torá, los libros de Samuel o libros proféticos como Isaías, Jeremías, etc.) dan cuenta de una intención compositiva precisa y deliberada. Es impensable que el tema central, el más esencial, es decir, Dios, haya sido tratado de modo marginal en cualquiera de estos libros. Al menos para los pasajes y libros citados en el párrafo anterior hay muchas indicaciones de una presentación sistemática del discurso sobre Dios. Por consiguiente, se debe suponer que sus autores han elaborado sus escritos conscientemente, dando máximo relieve a aquel por quien se sentían inspirados y hacia el cual querían orientar a sus lectores/oyentes. Por ende, es justo hablar de "teologías".

\section{Algunas orientaciones}

\subsection{Comenzar con los textos (no con "estratos", teorías o conceptos)}

Algunos de los grandes representantes de la teología bíblica (G. von Rad, H. D. Preuß, R. Albertz y otros ${ }^{5}$ ) tienden a subordinar los mensajes de textos particulares a conceptos más amplios, como Heilsgeschichte ("historia de la salvación"), Erwählung ("elección”), etc. Así intentan poner "orden" en la casi infinita variedad y riqueza de modos en los cuales la Biblia habla de Dios. Pueden subrayar algunos temas importantes, pero con esto se arriesgan a perder la amplia gama y detalles tanto de libros como de textos particulares.

En contra de aproximaciones "globales" (y "sistematizadoras") de este tipo, es necesaria una metodología aún más sólida.

En un primer paso es seguro y más provechoso empezar prestando atención sobre todo a los perfiles específicos de Dios presentados en los textos y en los libros ${ }^{6}$, así como están delineados, con expresiones repetidas frecuentemente (véanse los ejemplos citados en 1.3) o con expresiones que solo aparecen una vez. Son ejemplos de esta última:

${ }^{5}$ Albertz, Religionsgeschichte Israels; Preuss, Theologie des Alten Testaments; von RAD, Theologie des Alten Testaments.

${ }^{6}$ Para un ejemplo, véase FISCHER, Theologien des Alten Testaments. 
- el "rocío", usado por Dios en Os 14,6 (invirtiendo la acusación de Os 6,4);

- el "muro de fuego" (como un firewall en los ordenadores) para él en Zac 2,9;

- el "escudo alrededor de mí", en Sal 3,4;

- el "autor de la belleza", en Sb 13,3, etc.

En un segundo paso se puede intentar una recolección de las características de la teología de un libro entero. El libro de Rut, por ejemplo: el nombre Yhwh aparece 18 veces, de las cuales 5 veces está ligado con el verbo ntn, "dar, donar". De estas cinco, la única mención de Yhwh puesta bajo la voz del narrador está en 4,13: "Yhwh le dio embarazo"7; las restantes menciones de "Yhwh" están puestas en boca de los personajes, de las cuales dos son únicas. La primera en 2,20: “iSea él bendecido por Yhwh, que no ha privado ni a los vivos ni a los muertos de su constante lealtad!" (con asdw); y la segunda en 4,14: "iSea alabado Yhwh, que no te hecho faltar uno que te rescate hoy!" (con $g$ 'l). De este modo se delinean ciertos acentos en la teología del libro de Rut: Yhwh es aquel que da, aquel que es siempre leal -hasta con los muertos- y aquel que viene en auxilio de las viudas.

En la misma línea se puede proseguir con otros libros del AT. Para este tipo de investigación se pueden agregar todavía algunas indicaciones útiles. Resulta fructífero prestar atención especialmente a posiciones de relieve, repeticiones, expresiones únicas y desarrollos:

- Posiciones de relieve: por ejemplo, Gn 1 visto como inicio absoluto es fundamental respecto al modo en el cual se habla de Dios. Similarmente, al final del libro son muy relevantes el testimonio sobre Dios (confesión de fe) dado por Jacob (Gn 48,15-16) y las últimas palabras de José (Gn 50,20.24-25).

- Repeticiones: véase más arriba Gn 2-3; Dt 32 (con "roca") y "el Santo de Israel" en Isaías.

- Expresiones únicas: las siete últimas citas tratadas más arriba son todas menciones únicas en la Biblia.

- Desarrollos: en Ez 9-11, Dios sale del templo de Jerusalén, y en Ez 43 regresa nuevamente. En el libro de Oseas $(9,15)$ se habla del odio divino contra su pueblo; sin embargo, en 14,5, ya al final del libro, se aclara que Dios ama a su pueblo gratuitamente.

7 El TM usa el verbo nātan, "dar, donar". Las versiones en español suelen adaptar la frase: "Y Yahvé hizo que concibiera" (BJ), "el Señor hizo que concibiera" (LBA y PER), “y Jehová permitió que concibiera” (RV). 


\subsection{El papel de la fe}

La Constitución dogmática Dei Verbum (12) propone para una adecuada aproximación a la palabra divina que el texto bíblico sea "leído en el mismo espíritu en el cual ha sido escrito" ". Esto sugiere una conformidad entre el autor bíblico y el lector "ideal" de la Biblia, ambos movidos por el mismo espíritu, que inspira tanto a los autores de los diversos libros sagrados como a los destinatarios a través de los siglos, y del mismo modo también a nosotros. Según mí propia experiencia, orar es la mejor preparación para acoger la Palabra de Dios, para abrirse a su mensaje y para ser inspirado de aquel modo que Dei Verbum visualiza como modelo.

Sin embargo, no se pueden pasar por alto los dos últimos siglos de investigación bíblica. La fe es esencial, pero el análisis de los textos y libros bíblicos requiere también el complemento de una aproximación racional. Tantas veces la Biblia habla desde un plano simbólico o presenta historias imaginarias (por ejemplo, Judit o Ester). Es necesario entonces respetar las diferencias entre las expresiones literarias y el mensaje de fondo que el autor bíblico quiere transmitir; debemos ser de verdad críticos en nuestras búsquedas. Para una verdadera teología bíblica, tanto fe como crítica deben ir de la mano.

\section{3. ¿Cómo interpretar el AT siendo cristiano?}

Un punto adicional es preguntarnos si hay diferencias de fondo entre una "teología bíblica" hecha por judíos y otra hecha por cristianos. En otras palabras, ¿debemos o podemos "bautizar" el AT bajo una perspectiva cristiana?

Me refiero aquí a un panel de discusión en el Congreso de la Society of Biblical Literature (SBL) en Baltimore, MD, en 2013. Los representantes del lado judío ${ }^{9}$ eran Marvin A. Sweeney, Andrea Weiss y Joel N. Lohr, quienes aducían varias razones por las cuales las dos modalidades de hacer teología bíblica son distintas: por el texto (original hebreo), por el canon (sin los libros de Baruc, Sirácida, Sabiduría, etc.) y por la interpretación referida hacia el "cumplimiento" en el NT, en Jesús.

8 Sacra Scriptura eodem Spiritu quo scripta est etiam legenda et interpretanda sit.

9 Un representante importante de esta posición es SWEENEY, Tanak, 3-41; en la misma dirección también presenta diferencias con la comprensión cristiana RomSHILONI, Hebrew Bible Theology. (La publicación de las conferencias de Baltimore se espera bajo el título What is Biblical Theology? M. SWEENEY [ed.] [SBL Resources for Biblical Study Monograph Series]). 
En este último punto tienen razón, si se piensa que muchos cristianos -hasta hace poco- no consideraban la primera revelación de Dios en el AT como equiparable a la del NT. Sin embargo, esto ha cambiado recientemente, entre otras razones gracias al documento de la Comisión Bíblica sobre El pueblo judio y sus Escrituras Sagradas en la Biblia cristiana (24 de mayo de 2001) ${ }^{10}$.

Según mi punto de vista, las dos teologías del AT, tanto la judía como la de alguien que crea en Jesús, no se deberían diferenciar necesariamente. Para un análisis serio es preciso respetar el sentido original del texto; de hecho, también nuestras investigaciones se basan en un original hebreo y buscan comprender lo que el texto quería decir en su tiempo. Ni siquiera los libros adicionales al canon hebreo son un obstáculo, dado que estos incluyen algunos motivos que en los otros libros del AT ya habían sido mayormente desarrollados. Por consiguiente, hoy en día es todavía más importante que nosotros, como cristianos, no despreciemos o devaluemos la primera revelación divina preservada en el AT; podemos y debemos apreciarla en su propio valor. Estoy convencido de que, en un primer momento, la interpretación "cristiana" debe estar en conformidad con la interpretación judía.

\section{Desafios para la teología bíblica del AT}

\subsection{Los libros bíblicos suelen oponerse a modos habituales de pensar}

\subsection{1. ¿Puede moverse Dios?}

Desde antiguo, e incluso hasta hoy, se pueden encontrar posiciones filosóficas que presentan a Dios "inmóvil", incapaz de sufrir e incapaz de "cambiar de idea". Contra tal racionamiento, el Dios bíblico se deja "mover" y "sufre", muestra emociones, dolor, ira, e incluso "llora". En Jr 9,9, Dios habla para afirmar: "Sobre los montes levantaré gemidos y lamentos, un llanto de luto..."; en Za 12,10, Dios declara: “... me mirarán a mí, a quien han traspasado" "11; según Gn 6,6-7 y Jr 18,8.10, Dios también puede arrepentirse ${ }^{12}$; Dt 30,3 y otros pasajes usan el verbo $\check{s} w b$, "volver, retornar", referido a Dios ${ }^{13}$, indicando así que él es capaz de cambiar.

10 Original francés: Le peuple juif et ses Saintes Écritures dans la Bible chrétienne.

11 Cf. Stiglmair, “Der Durchbohrte”, 455.

12 DöHLING, Der bewegliche Gott; SONNET, “God's Repentance”.

13 Ehrenreich, Wähle das Leben!, 144-146. 


\subsection{2. ¿Puede Dios obrar en el mundo?}

También en la filosofía se encuentran algunas corrientes que sostienen que Dios es incapaz de actuar en el mundo. Contra esto, la Biblia afirma en innumerables ocasiones que Dios sí puede intervenir, y de hecho lo hace. $\mathrm{Al}$ respecto, es de particular importancia el modo en que se presentan los eventos en Ex 4-14 y su conexión con el motivo del "endurecimiento" del corazón ${ }^{14}$. Ex 9,34-10,1 presenta en secuencia tres casos sobre el endurecimiento del corazón: primero, en el v. 34, antes de la conclusión del séptimo signo, el de la granizada, dice que "el faraón se obstinó"; segundo, en el v. 35 amplía diciendo que "el corazón del faraón se obstinó"; por último, el v. 10,1 abre el octavo signo, el de las langostas, donde Dios declara: "Yo he hecho / hago pesado [kbd hifil] su corazón".

De este modo se ve cómo la acción se desarrolla gracias a la colaboración de los tres "planos": el faraón, su corazón (como expresión de procesos internos que no siempre se pueden referir) y Dios mismo.

\subsubsection{El peligro de generalizar}

Dentro de la teología, algunas teologías dogmáticas (y algunos exegetas también, como se ha mencionado más arriba) tienden a "sistematizar" el modo en que la Biblia habla de Dios. La riqueza y la variedad de los libros bíblicos desafían estos intentos e invitan a dejar a Dios más "libre", sin que tenga que corresponder con lógicas humanas. Por ejemplo, Os 5 habla de él con las metáforas de una "polilla" ( 'āš) y de "putrefacción" (rāqāb, v. 12), o lo compara con un "león" (kepîr, v. 14). En Os 14, a la imagen del "rocío" (v. 6) se agrega otra imagen de la naturaleza, el "ciprés verde" (v. 9).

Es común encontrar en poco espacio metáforas de Dios tan variadas. Isaías, por ejemplo, habla de Dios como "nuestro padre" (Is 63,16; 64,7), pero lo presenta también con rasgos típicos de una "madre" (Is 49,15; 66,13). El libro de Jeremías puede declarar que Dios no tiene piedad de su pueblo ( Jr 13,14), y en oposición puede decir que tiene piedad en gran medida (Jr 31,20). Este último ejemplo deja en claro que la Biblia no evita las contraposiciones.

14 Un estudio más exhaustivo sobre este argumento es el de Kellenberger, Die Verstockung Pharaos. 
En resumen, la expectativa de que Dios sea "uniforme", claro y casi "unívoco" se desvanece. La Biblia -deliberadamente- combina imágenes varias, incluso en tramos cortos, y prefiere mostrar a Dios "vivo" en el tejido dinámico de las narraciones; como muestra Friedhelm Hartenstein, hay un equilibrio entre rasgos estables y cambiantes en Dios ${ }^{15}$. Por consiguiente, se nos invita a dejar a Dios en "libertad", sin limitarlo con nuestros conceptos e ideas. Es decir, se debe tener una disposición que corresponda con aquello que él es, en una infinita variedad de aspectos, superando cada intento humano de expresar "enteramente" su ser. La manera multiforme con la cual la Biblia habla de él es el único modo adecuado para él; un modo que también está ligado a la prohibición de hacerse ídolos, emitida en el "Decálogo" (Ex 20,4). La amplitud de la revelación divina jamás podrá ser abarcada completamente; lo cual, por un lado, nos marca, mientras estemos vivos, un camino y una tarea sin fin, y, por otro, nos enseña a ser humildes.

\subsection{4. ¿Hay arbitrariedad en el hablar de Dios en la Biblia?}

Sin embargo, aquí surge un problema hermenéutico. Las múltiples teologías de la Biblia conducen a dificultades internas en la tarea de elaborar una "teología bíblica", mientras que esta existe solamente en plural. Estamos ante el riesgo de perdernos en la multiplicidad y de llegar a una arbitrariedad que no permita reconocer qué cosa es relevante para una teología bíblica fructífera. ¿Cómo evitar este peligro? ¿Cuáles son los criterios para sopesar la importancia o pertinencia de un texto, tema o imagen de Dios respecto a otros posibles dentro del texto bíblico?

Según la opinión de muchos, la mía inclusive, una clave radica en la revelación divina expuesta en Ex 34,6-7. Matthias Franz la llama Gnadenrede ("fórmula de la misericordia") ${ }^{16}$. Dios mismo se presenta a Moisés como rahûm we国annûn, "misericordioso y clemente" sin medida, pero al mismo tiempo "justo". A menos de seis semanas después de haber sellado la Alianza, el pueblo ya la había quebrantado con el becerro de oro (Ex 32). Con la Gnadenrede, Dios responde a la ruptura de la Alianza mostrando la preponderancia de su "clemencia", pero sin relegar el aspecto de la "justicia".

15 Cf. Hartenstein, “JHWHs Wesen”, 13-17.

${ }^{16}$ Franz, Der barmherzige und gnädige Gott, ya en el subtítulo y muy a menudo. 
El perdón caracteriza al Dios bíblico, y en torno a este "centro" ${ }^{17}$ se deben organizar e interpretar todas las demás afirmaciones y textos del AT.

\subsection{Desafíos del presente}

No basta con reconocer los desafíos que la Biblia nos presenta en los campos espiritual e intelectual. Se necesita mirar más allá y tener en cuenta que las teologías bíblicas son relevantes para abordar las preguntas y los problemas cruciales del mundo y de la sociedad actuales.

\subsubsection{La violencia}

En años recientes, a menudo se ha usado de modo equivocado la palabra "Dios" para fundamentar acciones violentas contra otros. ¿Cómo podemos evitar semejantes interpretaciones de los textos relevantes?

También en la Biblia se encuentran pasajes que parecen insinuar violencia; no obstante, estos hablan en gran parte con estilos del pasado que no corresponden con la realidad actual, de hecho la deforman. Por ende, es necesario criticar estos estilos del pasado, también porque ellos dan testimonio del lado "humano", limitado, de algunos textos bíblicos.

Desde el punto de vista positivo se debe notar que la Biblia jamás ha llamado a ejecutar acciones violentas en el presente. No es posible referirse a los textos bíblicos, en el presente, para legitimar asesinatos o cualquier otro daño a los demás. Lo más esencial siempre será orientarse hacia el carácter misericordioso de Dios (véase más arriba Ex 34).

\subsubsection{El desinterés por Dios}

Evidentemente, gran parte de la sociedad del presente no concede mayor relevancia a Dios. El libro de los Salmos también refiere esta posición (cf. Sal 10,4.11; 14,1: “¡No hay Dios!”). ¿Podemos, entonces, demostrar el valor de los modos con que la Biblia habla de Dios?

17 Sobre la búsqueda de un centro teológico en la Biblia, véase también OEMING, “Viele Wege zu dem Einen"; él habla del "centro trascendental” (83), el cual lo percibe en Yhwh, quien permanece en una diversidad de aspectos mayores, "el misterio del mundo" (103-104). El perdón de Dios no es una categoría generalizada, sino una idea eje que permite focalizar muchos aspectos relevantes, a diferencia de las sistematizaciones mencionadas al inicio de 2.1. 
En primera instancia es útil volver la mirada a la historia de la humanidad y de las religiones: no hay "personaje" alguno que haya tenido un influjo mayor que Yhwh ${ }^{18}$. Debemos tomar conciencia que no solamente nuestras culturas occidentales, sino todo el mundo ha sido influido y marcado por las expresiones de fe y por las personas que creen en Yhwh, mucho más que cualquier otro factor humano.

En segunda instancia se puede notar que la Biblia contiene un entramado de experiencias de redención y de salvación recogidas a través de más de un milenio en diversas circunstancias. En la multiplicidad de libros del AT, la Biblia habla del milagro de una comunidad (Israel) que era insignificante ante las grandes culturas y poderes del Oriente antiguo; y, sin embargo, ella ha sido la única en sobrevivir hasta nuestros días, no obstante las terribles persecuciones. A causa de esto, el AT contiene un riquísimo tesoro de sabiduría humana y de conocimiento respecto a la relación con Dios. Solo un necio podría negar esta realidad y echar en saco roto este testimonio bíblico que ha sido puesto en práctica como luz, alegría y fuerza a lo largo de todo el tiempo de su existencia.

\subsubsection{La invitación a orar e imitar a Dios}

Más aún, no se trata solamente de dedicarse a hablar acerca de Dios. El ejemplo del libro de Job lo muestra claramente: Los amigos de Job solamente hablan acerca de Dios; mientras que Job es el único que se dirige $a$ Dios, y lo hace con frecuencia ${ }^{19}$. Ante tal disposición, el lector es invitado también a orar como Job. La Biblia entera puede ser asumida como el libro que enseña la oración e invita a orar, una y mil veces.

Pero todavía más allá se debe decir que, en última instancia, la Biblia quiere volvernos “discípulos” de Dios (Is 54,13, reasumido en Jn 6,45), quiere incitarnos a imitarlo en santidad ( $\operatorname{Lv} 11,44-45$ : "iSed santos, porque yo soy santo!”), imitarlo en perfección (Mt 5,48: “iSed, por tanto, perfectos como perfecto es vuestro Padre celestial!") e imitarlo en misericordia (Lc 6,36: "iSed misericordiosos como misericordioso es vuestro Padre!”). Que estas bellas consonancias entre ambas partes de la revelación divina, entre el Antiguo y el Nuevo Testamento, sean una apropiada conclusión para esta reflexión sobre las teologías de la Biblia.

18 LANG, Jahwe der biblische Gott, 7.

19 Ejemplos son Job 7,12-21; 9,31; 13,20-28; 14,3-6.13-20, etc. 


\section{Bibliografía}

Albertz, R., Religionsgeschichte Israels in alttestamentlicher Zeit. Teil 1: Von den Anfängen bis zum Ende der Königszeit. Teil 2: Vom Exil bis zu den Makkabäern, Göttingen 1992.

CRoAtto, J. S., Exilio y sobrevivencia. Tradiciones contraculturales en el Pentateuco. Comentario de Génesis 4-11, Buenos Aires 1997.

-, Hermenéutica bíblica. Para una teoría de la lectura como producción de sentido, Buenos Aires 2000.

-, Historia de salvación: la experiencia religiosa del pueblo de Dios, Estella 2001.

DöHLIng, J.-D., Der bewegliche Gott: eine Untersuchung des Motivs der Reue Gottes in der Hebräischen Bibel (HBS 61), Freiburg 2009.

Ehrenreich, E., Wähle das Leben! Deuteronomium 30 als hermeneutischer Schlüssel zur Tora (BZAR 14), Wiesbaden 2010.

Fischer, G., Jeremia 26-52 (HThKAT), Freiburg 2005.

-, Theologien des Alten Testaments (NSK-AT 31), Stuttgart 2012.

Franz, M., Der barmherzige und gnädige Gott: Die Gnadenrede vom Sinai (Exodus 34,6-7) und ihre Parallelen im Alten Testament und seiner Umwelt (BWANT 160), Stuttgart 2003.

HaRtenstein, F., "JHWHs Wesen im Wandel: Vorüberlegungen zu einer Theologie des Alten Testaments", ThLZ 137 (2012) 3-20.

Kellenberger, E., Die Verstockung Pharaos: Exegetische und auslegungsgeschichtliche Untersuchungen zu Exodus 1-15, Stuttgart 2006.

LANG, B., Jahwe der biblische Gott, München 2002.

Mesters, C., Deus, onde estás? Uma introduÇÃo prática à Bíblia, Petrópolis 2010.

-, O PROFETA JEREMIAS: UM HOMEM APAIXONADO, São Paulo 2016.

Oeming, M., "Viele Wege zu dem Einen. Die 'transzendente Mitte' einer Theologie des Alten Testaments im Spannungsfeld von Vielheit und Einheit", en S. BEYerLe - A. GraupNer - U. RÜTERSWÖRdEN (eds.), Viele Wege zu dem Einen. Historische Bibelkritik - Die Vitalität der Glaubensüberlieferung in der Moderne (BThSt 121), Neukirchen-Vluyn 2012, 83-108.

Preuss, H. D., Theologie des Alten Testaments. Band 1: JHWHs Erwählendes und verpflichtendes Handeln. Band 2: Israels Weg mit JHWH, Stuttgart 1991-1992.

RaD, G. von, Theologie des Alten Testaments. Band 1: Die Theologie der geschichtlichen Überlieferungen Israels. Band 2: Die Theologie der prophetischen Überlieferungen Israels, München 1960. 
Rom-Shiloni, D., "Hebrew Bible Theology: A Jewish Descriptive Approach", JR 96 (2016) 165-184.

Sedlmeier, F., Das Buch Ezechiel. Kapitel 25-48 (NSK-AT 21/2), Stuttgart 2013.

Sonnet, J.-P., "God's Repentance and 'False Starts' in Biblical History (Genesis 6-9; Exodus 32-34; 1 Sam 15 and 2 Samuel 7)", en A. LemaIRE (ed.), Congress Volume Ljubljana 2007 (VTS 133), Leiden 2010, 469-494.

Stiglmair, A., "Der Durchbohrte - ein Versuch zu Sach 12”, ZKTh 116 (1994) 451-456.

Sweeney, M., Tanak. A Theological and Critical Introduction to the Jewish Bible, Minneapolis 2012.

(recibido: 28/06/17 - aceptado: 01/10/17) 